\title{
STUDIES OF ANTI-HYPERTENSIVE ACTIVITY OF
}

\section{1, 4-DIHYDROPYRIDINE DERIVATIVES: COMBINATIONS OF DFT-QSAR AND DOCKING APPROACHES}

\author{
Abel Kolawole Oyebamiji and Banjo Semire* \\ Department of Pure and Applied Chemistry, Ladoke Akintola University of Technology, Ogbomoso, \\ Oyo State, Nigeria \\ *E-mail: bsemire@lautech.edu.ng \\ Tel.: +2348038269809 .
}

Received: Dec 16, 2016 / Revised: Dec 30, 2016 / Accepted: Dec 30, 2016

\begin{abstract}
1,4-Dihydropyridine (1,4-DHP) derivatives have been recognized as calcium channel blocker (CCB) agent. In this research, a series of 1,4-dihydropyridine (1,4-DHP) derivatives were theoretically examined for inhibitory activity against hypertension using density functional theory (DFT), quantitative structure activity relationship (QSAR) and docking approaches. The calculated molecular descriptors from DFT were used to develop QSAR model that related the descriptors to the bioactivity (IC50). The QSAR analysis indicated that the energy of highest occupied molecular orbital (HOMO), dipole moment, solvation energy and average of electronic charges on heteroatoms are crucial parameters for the observed biological activity. The QSAR model predicted bioactivity $\left(\mathrm{IC}_{50}\right)$ agreed well with the experimental $I_{50}$. All these compounds were docked against hypertensive cell receptors (PBD: IIMT) and the binding free energy of ligand-receptor interactions agreed with the observed bioactivity $\left(\mathrm{IC}_{50}\right)$ of the 1, 4-DHPs with the receptor.
\end{abstract}

Key words: 1, 4-Dihydropyridine derivative, Calcium channel blocker, DFT, QSAR, Docking.

\section{INTRODUCTION}

Calcium channel blockers (CCBs) are drugs with heterogeneous set of compounds, categorized according to chemical structure such as dihydropyridines and diphenylalkylamines. CCBs also known as calcium antagonists help in the treatment of hypertension. CCBs act through voltage-dependent $\mathrm{Ca}^{2+}$ channel by preventing the entrance of calcium ions into cardiac and vascular smooth muscle cells (Lip and Beevers, 2001).

Hypertension, a diastolic blood pressure with BP greater than $90 \mathrm{mmHg}$ and systolic blood pressure with BP greater than $140 \mathrm{mmHg}$, is the only risk factor that develops stroke, congestive heart failure, chronic kidney disease, and coronary artery disease and eventually leads to deaths (Ogah and Rayner, 2013). Hypertension is easily identified and can be managed if the patients undergo effective treatment but yet to be effectively controlled especially with people that as advanced in age (Havas et al 1993; Whitworth, 2003).

Chemotherapy is one of effective ways of managing hypertension and among CCBs, 1, 4dihydropyridines (DHPs) are well known for their effectiveness. DHP is a pyridine based molecule and the parent to a set of molecules which are semi-saturated with two substituents that replace one double bond. They are well recognized in pharmacology as L-type calcium channel blockers, as well as in the treatment of hypertension. Therefore, the structural features of 1,4-DHPs are well recognized as essential descriptors for their bioactivity as drugs that treat hypertension. Several DHPs class L-type 
calcium channel blockers which have been commercialized include felodipine, nifedipine, nicardipine (Oyebamiji and Semire, 2016; ALJumali, 2015).

Quantitative structural activity relationship (QSAR) models are regression simulations useful in the chemical and biological sciences analysis. In QSAR modeling, the molecular descriptors which are the predictors recapitulate the link between biological activity $\left(\mathrm{IC}_{50}\right)$ and the generated descriptors in a series of molecules in order to predict the activities of newly sets of molecule (Nantasenamat et al 2009; Tropsha, 2010). However to develop a good and functional QSAR model, higher quality data, the choice of descriptors and statistical methods used for modeling are of paramount importance in QSAR modeling (Wold and Eriksson, 1995).

Molecular docking as a growing essential device for drug discovery is a main tool in structural molecular biology and computer-based drug design (Sharma et al 2011; Balasubramanian and Vijaya Gopal, 2012; Sharma and Kumar, 2014). It can be used to execute virtual screening on huge set of compounds, scoring and expose how the ligands prevent the target binding site, which is important in optimization (Morris and Lim-Wilby, 2008). Two popular methods in molecular docking are (i) matching technique which describes the protein and the chemical compound (ligand) as complementary surfaces and (iii) the second method mimics the real docking process that calculate the ligand-protein interaction energies which was used for the

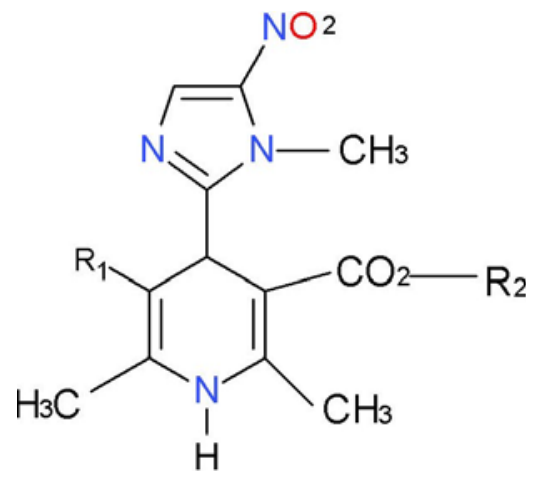

present work (Meng et al 1992; Goldman and Wipke, 2000).

Seven compounds, previously studied for their bioactivity as calcium antagonists (Miri et al 2008), were optimized using DFT method for the calculations of molecular descriptors in the present study. These compounds are 3isopropyl-5- nitro-2,6- dimethyl- 4- (1-methyl-5nitro-1H-imidazol-2-yl)- 1,4-dihydropyridine-3carboxylate $\left(\mathrm{B}_{1}\right)$, 3-ethyl-5-cyano-2,6-dimethyl4- (1- methyl- 5-nitro- $1 \mathrm{H}$-imidazol- 2-yl)- 1,4dihydropyridine-3-carboxylate $\left(\mathrm{B}_{2}\right)$, 3-(2-cyano ethyl)- 5-cyano- 2,6- dimethyl- 4- (1-methyl-5nitro- $1 H$-imidazol-2-yl)- 1,4- dihydropyridine-3carboxylate $\left(\mathrm{B}_{3}\right)$, 3-isopropyl-5-Cyano-2,-6dimethyl- 4- (1-methyl- 5-nitro- $1 \mathrm{H}$-imidazole-2yl)-1,4-dihydropyridine-3-carboxylate $\left(\mathrm{B}_{4}\right), 3$ propyl- 5- cyano- 2,6- dimethyl- 4-(1-methyl-5nitro- $1 H$-imidazol-2-yl)- 1,4-dihydropyridine-3carboxylate $\left(\mathrm{B}_{5}\right), 3$-butyl-5-cyano-2,6-dimethyl4- (1- methyl- 5-nitro- $1 \mathrm{H}$-imidazol- 2-yl)-1,4- dihydro pyridine-3-carboxylate $\left(\mathrm{B}_{6}\right)$ and 3-methyl5-cyano- 2,6- dimethyl- 4-(1-methyl- 5-nitro$1 \mathrm{H}$ - imidazol- 2-yl)-1,4- dihydropyridine- 3carboxylate $\left(\mathrm{B}_{7}\right)$ (Figure 1). The major objectives of the present study are (i) to use quantum chemical method via DFT to calculate molecular descriptors, (ii) to use calculated descriptors to develop QSAR model that relates the descriptors to the observed bioactivity and (iii) to find suitable conformation as well as calculations of binding affinity of these compounds through molecular docking to the targeted receptor (PDB: 1IMT).

Fig. 1. The schematic structures of the studied molecules

\section{Computational details \\ Quantum chemical method}

Conformational search was performed on the 1 , 4-DPHs derivatives considered in this research work employing semi-empirical AM1 method with Monte Carlo search algorithm and the lowest-energy conformer of this conformational search was taken for further DFT calculations. The equilibrium geometries for all the lowestenergy conformers were optimized at Density Functional Theory (DFT) with the standard 6$31 \mathrm{G}(\mathrm{d}, \mathrm{p})$ basis set.

The DFT method used consist of the threeparameter density functional, that includes 
Becke's gradient exchange correction (Becke, 1993) and the Lee, Yang, Parr correlation functional (i.e. B3LYP) (Lee et al 1988). The choice of the selected functional and basis sets was attributed to the accuracy of DFT calculations and the selected basis set, 6-31G $(d, p)$ has been proved to be sufficient for calculation of the excited properties of ligands. The studied molecules were optimized to generate molecular descriptors that described the bioactivity $\left(\mathrm{IC}_{50}\right)$ of the compounds. Also, the optimized structures were used for molecular docking.

Some of the molecular parameters calculated are the LUMO, the HOMO, dipole moment and global molecular descriptors such as chemical hardness, softness and chemical potential. Solvation energy using SM5.4 model, a semiempirical method (AM1) as implemented on quantum chemical software, Spartan 10 and molecular descriptors, calculated using quantum mechanical methods have been used in many QSAR studies (Todeschini and Consonni, 2000; Eroğlu et al 2007).

Furthermore, the selected descriptors were used to develop quantitative structure-activity relationship (QSAR) model that relates cytotoxicity to the molecular descriptors of the compounds (Goodarzi et al 2012). Multiple linear regression (MLR) analysis, a frequent statistical and mathematical method was used to develop the QSAR model. The QSAR studies have been tools of predicting endpoints of interest in organic molecules acting as drugs (Karelson, 2000).

The calculated molecular descriptors used in QSAR studies using DFT method have better correlation to the experimental data than those calculated form semi-empirical methods (Stewart, 1989; Dewar et al 1985; Zhang et al 2004; Singh et al 2004).

Finally, molecular docking was performed on the compounds to find suitable conformation as well as calculations of binding affinities. The X-ray crystal of the 1IMT protein complex (PDB ID: 1IMT) was obtained from protein data bank (Liu et al 1996). Discovery studio was used to treat the receptor by removing the ligands, water molecules, and cofactors that were present (Biovia, 2005). Autodock tool was used to convert the protein and the ligands to pdbqt format and the docking analysis was performed using AutoDockVina, which Darwinian evolution theory motivated to be iterative optimization method (Rani et al 2014).

\section{RESULTS AND DISCUSSION \\ Molecular descriptors}

The most stable conformation of each 1,4-DHPs was considered for geometry optimization at B3LYP/6-31G** level of theory for the calculation of essential molecular descriptors that could be used to describe the cytotoxicity of the compounds. The molecular descriptors that were calculated include the HOMO and LOMO energies, solvation energy, polar surface area (PSA), dipole moment (DM), weight, hydrophobicity (log P), volume (V), area, ovality and heteroatoms (average of electronic charges on all heteroatom in the compound). The calculated frontial molecular orbital (HOMO, LUMO, band gap) energies were $-5.79,-1.69$ and $4.17 \mathrm{eV}$ for $\mathrm{B}_{1} ;-5.26,-1.55$ and $3.71 \mathrm{eV}$ for $\mathrm{B}_{2}$; $5.56 \mathrm{eV},-1.67 \mathrm{eV}$ and $3.89 \mathrm{eV}$ for $\mathrm{B}_{3} ;-5.68 \mathrm{eV}$, $1.36 \mathrm{eV}$ and $4.32 \mathrm{eV}$ for $\mathrm{B}_{4} ;-5.20 \mathrm{eV}, 0.67 \mathrm{eV}$ and $4.53 \mathrm{eV}$ for $\mathrm{B}_{5} ;-5.26,-1.62 \mathrm{eV}$, and $4.00 \mathrm{eV}$ for $\mathrm{B}_{6}$; and $-5.58 \mathrm{eV},-1.28 \mathrm{eV}$ and $4.30 \mathrm{eV}$ for $\mathrm{B}_{7}$ for HOMO, LUMO and band gap respectively (Table 1). Since, HOMO energy relates to the ability of a molecule to donate electrons to the surrounding receptor and likewise lower LUMO enhances the ability of a molecule to accept electrons form the receptor.

Also, lower the band gap energy leads to easy excitation of electrons and facilitates better ability of a molecule to donate the electron to the surrounding molecule. Therefore, it is expected that HOMO and LUMO energies as well as band gap energy should play crucial roles in binding of the ligand to the receptor, thus enhances nonbonding interactions such as hydrogen bonding and hydrophilic interactions. However, know clear relationship was found between the cytotoxicity of these compounds and the LUMO or band gap energies, only HOMO energies showed a fair correlation as shown in Figure 1. Similarly, the values of other parameters calculated such as $\log \mathrm{P}$, dipole moment (DM), ovality and solvation energy show no clear relationship with the observed anti-hypertensive activities of these compounds.

\section{Generation of QSAR model using multiple linear regressions}

Pearson's matrix expresses the liaison among bioactivities of molecular descriptors against CCB. The positive correlation between the $\mathrm{IC}_{50}$ and HOMO is 0.813 and the negative correlation between the $\mathrm{IC}_{50}$ is -0.503 .

These correlation are fair since $\mathrm{R}^{2}$ is greater than the 0.5. Other descriptors are fair in their 
relationship to each other, for example, HOMO is correlated to LUMO by 0.622 , Dipole moment is correlated to solvation energy by 0.695 , dipole moment is correlated to heteroatom by 0.803 and solvation energy is correlated heteroatom by 0.803 . Also, the followings are negatively correlated to each other; HOMO is correlated with solvation energy by -0.664 , dipole moment is correlated to LUMO by -0.778 , solvation energy is correlated to LUMO by -0.902 and heteroatom is correlated to LUMO by -0.7777 (Table 2).

Table 1. Selected molecular parameters obtained by B3LYP/6-31G** for anti-hypertensive

\begin{tabular}{|c|c|c|c|c|c|c|c|}
\hline Mol & $\begin{array}{c}\text { HOMO } \\
(\mathbf{e V})\end{array}$ & $\begin{array}{c}\text { LUMO } \\
(\mathbf{e V})\end{array}$ & $\begin{array}{c}\mathbf{S E} \\
\mathbf{k J} / \mathbf{m o l}\end{array}$ & $\mathbf{B G}$ & $\begin{array}{c}\mathbf{D M} \\
(\mathbf{D e b y e})\end{array}$ & $\mathbf{j}$ & $\boldsymbol{\mu}$ \\
\hline $\mathrm{B}_{1}$ & -5.79 & -1.69 & -19.12 & 4.10 & 3.88 & 2.05 & -3.74 \\
\hline $\mathrm{B}_{2}$ & -5.26 & -1.55 & -60.30 & 3.71 & 6.31 & 1.86 & -3.41 \\
\hline $\mathrm{B}_{3}$ & -5.56 & -1.67 & -82.80 & 3.89 & 4.26 & 1.95 & -3.62 \\
\hline $\mathrm{B}_{4}$ & -5.68 & -1.36 & -48.59 & 4.32 & 2.73 & 2.16 & -3.52 \\
\hline $\mathrm{B}_{5}$ & -5.20 & -0.67 & -49.37 & 4.53 & 1.03 & 2.27 & -2.94 \\
\hline $\mathrm{B}_{6}$ & -5.62 & -1.62 & -56.61 & 4.00 & 6.26 & 2.00 & -3.62 \\
\hline $\mathrm{B}_{7}$ & -5.58 & -1.28 & -76.65 & 4.30 & 3.48 & 2.15 & -3.43 \\
\hline
\end{tabular}

Table 1. Contd.

\begin{tabular}{|c|c|c|c|c|c|c|c|c|}
\hline Mol & $\mathbf{\omega}$ & $\mathbf{H}$ & $\mathbf{M W}(\mathbf{a m u})$ & $\mathbf{l o g} \mathbf{P}$ & Ovality & $\mathbf{V}\left(\mathbf{A}^{\mathbf{3}}\right)$ & $\mathbf{A}\left(\mathbf{A}^{\mathbf{2}}\right)$ & $\mathbf{P S A} \mathbf{( A}^{\mathbf{2}} \mathbf{)}$ \\
\hline $\mathrm{B}_{1}$ & 0.29 & -0.93 & 462.37 & 0.68 & 1.63 & 370.52 & 407.14 & 82.55 \\
\hline $\mathrm{B}_{2}$ & 0.32 & -0.94 & 333.35 & -0.69 & 1.54 & 326.12 & 353.11 & 102.03 \\
\hline $\mathrm{B}_{3}$ & 0.30 & -0.97 & 358.36 & -0.66 & 1.59 & 346.16 & 378.02 & 115.40 \\
\hline $\mathrm{B}_{4}$ & 0.35 & -0.98 & 347.38 & -0.38 & 1.58 & 344.56 & 374.66 & 99.33 \\
\hline $\mathrm{B}_{5}$ & 0.53 & -1.01 & 351.41 & -1.20 & 1.60 & 354.43 & 386.76 & 108.05 \\
\hline $\mathrm{B}_{6}$ & 0.31 & -0.94 & 361.40 & 0.21 & 1.60 & 363.00 & 393.64 & 101.86 \\
\hline $\mathrm{B}_{7}$ & 0.37 & -0.94 & 319.32 & -1.03 & 1.51 & 307.68 & 333.26 & 102.85 \\
\hline
\end{tabular}

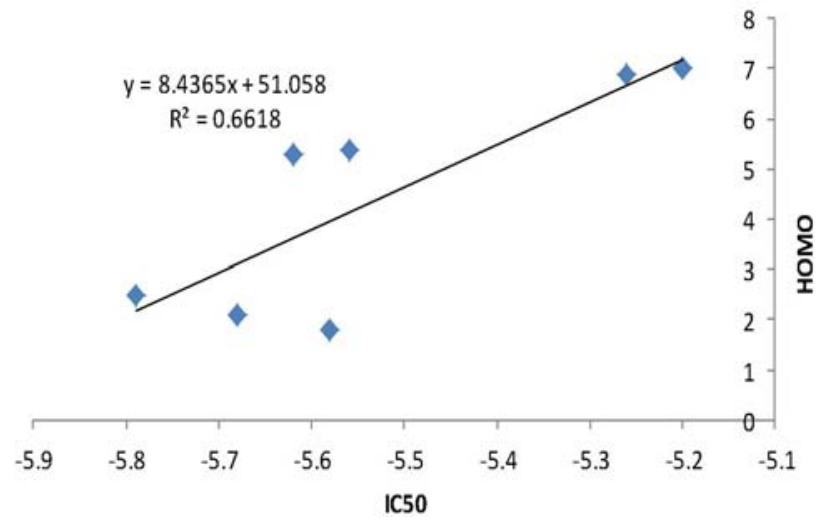

Fig. 1. Correlation between $\mathrm{IC}_{50}$ and the HOMO energies $(\mathrm{eV})$

Moreover, the fitting value is not sufficient to authenticate the enactment of QSAR, therefore, the statistical analysis are carried out as described methodology to calculate the predicted $\mathrm{R}^{2}(0.999)$ which shows the promising reproductive power of this QSAR model as displayed in equation 1 . Calculated regression parameters for 1, 4-DHPs used in the validation of QSAR model for anti-hypertensive activity includes $\mathrm{R}^{2}, \mathrm{CV} \cdot \mathrm{R}^{2}, R^{2}$ as shown in Table 3. The calculated $R^{2}$ (0.996) revealed a good fitness. The calculated CV.R ${ }^{2}(0.996)$ revealed the reliability of the model, since it is greater than 0.5 (Ponce et al 2004). $R^{2}{ }_{a}$ was calculated to be 0.976. This make the QSAR model to be predictive since it is greater than 0.6.The calculated bioactivity $\left(\mathrm{IC}_{50}\right)$ is fitted $\left(\mathrm{R}_{2}=0.996\right)$ into the experimental values as shown in the Figure 2.

\section{Docking and scoring}

CCBs are several medications that disturb the drive of calcium $\left(\mathrm{Ca}^{2+}\right)$ through calcium channels. Calcium channel blockers are used as antihypertensive drug i.e. as medications to decrease blood pressure in patients with hypertension. Ligands used as antihypertensive are particularly effective against large vessel stiffness which is one of the common causes of elevated systolic blood pressure in elderly patients (Olson, 2011). 
Table 2. Pearson's correlation matrix for descriptors

\begin{tabular}{|c|c|c|c|c|c|c|}
\hline & IC $_{\mathbf{5 0}}$ & HOMO & DM & SE & HETEROATOM & LUMO \\
\hline IC $_{\mathbf{5 0}}$ & 1.000 & & & & & \\
\hline HOMO & 0.813 & 1.000 & & & & \\
\hline DM & 0.191 & -0.130 & 1.000 & & & \\
\hline SE & -0.503 & -0.664 & 0.695 & 1.000 & & \\
\hline HETEROATOM & -0.312 & -0.453 & 0.803 & 0.803 & 1.000 & \\
\hline LUMO & 0.247 & 0.622 & -0.778 & -0.902 & -0.777 & 1.000 \\
\hline
\end{tabular}

Table 3. Evaluation of the QSAR model for CCB

\begin{tabular}{ccccc} 
Equation & $\mathrm{N}$ & $\mathrm{R}^{2}$ & $\mathrm{CV}^{2}$ & $R_{a}^{2}$ \\
\hline$-10.534+5.601(\mathrm{HOMO})+0.837(\mathrm{DM})-0.241(\mathrm{SE})-36.908(\mathrm{H})-$ & 7 & 0.996 & 0.996 & 0.976 \\
$4.597(\mathrm{LUMO})---1$ & & & &
\end{tabular}

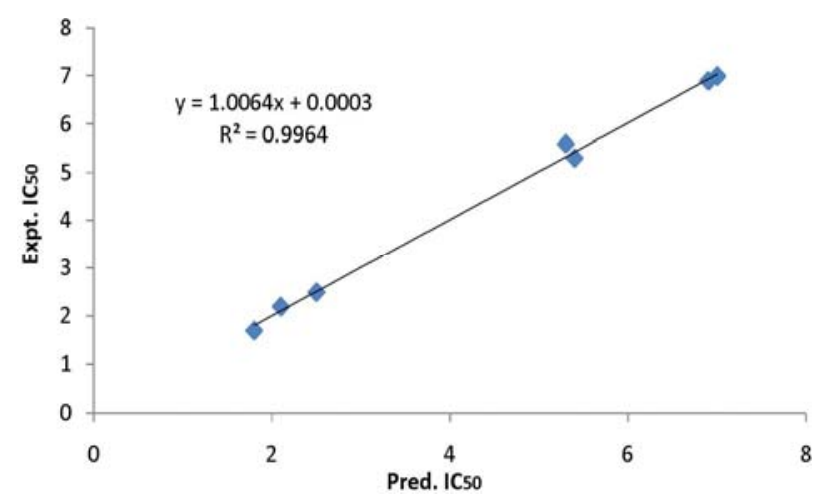

Fig. 2. Correlation between experimental and predicted $\mathrm{IC}_{50}$

Therefore, molecular docking simulations were performed on the optimized structures of these compounds obtained at DFT level against 1IMT and the conformation in each ligand-receptor complex with highest free energy of interactions was taken. The conformation with utmost binding energy in each docking is presumed to be the best conformation. Therefore, the free energy of the interactions (docking scores) for these compounds were $-4.10 \mathrm{kCal} / \mathrm{mol}$ for $\mathrm{B}_{1}$, -
$3.90 \mathrm{kCal} / \mathrm{mol}$ for $\mathrm{B}_{2},-4.30 \mathrm{kCal} / \mathrm{mol}$ for $\mathrm{B}_{3},-3.00$ $\mathrm{kCal} / \mathrm{mol}$ for $\mathrm{B}_{4},-4.10 \mathrm{kCal} / \mathrm{mol}$ for $\mathrm{B}_{5},-3.60$ $\mathrm{kCal} / \mathrm{mol}$ for $\mathrm{B}_{6}$ and $-4.10 \mathrm{kCal} / \mathrm{mol}$ for $\mathrm{B}_{7}$ as presented in Table 4. It was observed the compounds formed a number of hydrogen bonds (HIs) with 1 IMT in the active site; $B_{2}, B_{5}, B_{6}$, and $\mathrm{B}_{7}$ formed four HIs each with 1IMT receptor, $\mathrm{B}_{3}$ and $\mathrm{B}_{4}$ formed three and five HIs with 1IMT respectively (Table 5). No HIs between $B_{1}$ and the receptor was observed, however $\mathrm{B}_{1}$ would be stabilized in the active site of 1IMT by other nonbonding interactions (Figure 3a).

Table 4. Docking scores for studied 1,4-dihydro pyridine derivatives

\begin{tabular}{|c|c|}
\hline Compound & Affinity (kcal/mol) \\
\hline$B_{1}$ & -4.10 \\
\hline$B_{2}$ & -3.90 \\
\hline$B_{3}$ & -4.30 \\
\hline$B_{4}$ & -3.00 \\
\hline$B_{5}$ & -4.10 \\
\hline$B_{6}$ & -3.60 \\
\hline$B_{7}$ & -4.10 \\
\hline
\end{tabular}

Table 5. Interactions among amino acid residues of 1IMT and ligands

\begin{tabular}{|c|c|c|c|}
\hline S. No. & $\begin{array}{c}\text { H-Bond between amino acid residues } \\
\text { and ligand }\end{array}$ & Distance & $\begin{array}{c}\text { No of } \\
\text { H-bonds }\end{array}$ \\
\hline $\mathrm{B}_{1}$ & Nil & Nil & Nil \\
\hline $\mathrm{B}_{2}$ & $\begin{array}{l}\text { (i) CYS-41 LIG:N (ii) ASP-40 LIG:0 } \\
\text { (iii) HIS-57 LIG:O (iv) HIS-57 LIG:O }\end{array}$ & $\begin{array}{l}2.9,3.2 \\
2.1,2.3\end{array}$ & 4 \\
\hline $\mathrm{B}_{3}$ & $\begin{array}{l}\text { (i) ASP-40 LIG:O (ii) CYS-59 LIG:N } \\
\text { (iii) CYS-59 LIG:N }\end{array}$ & $\begin{array}{l}3.0,3.5 \\
2.4 \\
\end{array}$ & 3 \\
\hline $\mathrm{B}_{4}$ & $\begin{array}{l}\text { (i) ASP-40 LIG:O (ii) CYS-41 LIG:0 } \\
\text { (iii) PHE-75 LIG: O (iv) LYS-73 LIG:0 } \\
\text { (v) CYS-41 LIG:0 }\end{array}$ & $\begin{array}{l}2.9,3.3 \\
2.3,2.8 \\
2.9\end{array}$ & 5 \\
\hline $\mathrm{B}_{5}$ & $\begin{array}{l}\text { (i) ASP-40 LIG:O (ii) HIS-57 LIG:O } \\
\text { (iii) HIS-57 LIG:O (iv) CYS-41 LIG:H }\end{array}$ & $\begin{array}{l}3.0,2.4 \\
1.9,2.1\end{array}$ & 4 \\
\hline
\end{tabular}




\begin{tabular}{|c|r|c|c|}
\hline \multirow{2}{*}{$\mathrm{B}_{6}$} & (i) CYS-41 LIG:N (ii) ASP-40 LIG:0 & $2.9,2.9$, & \\
\hline \multirow{2}{*}{$\mathrm{B}_{7}$} & (iii) HIS-57 LIG:O (iv) HIS-57 LIG:O & $2.4,2.1$ & 4 \\
& (i) CYS-41 LIG:N (ii) HIS-57 LIG:0 & $3.1,2.3$, & 4 \\
\hline
\end{tabular}

The binding modes of all the seven compounds in the active site of 1IMT are shown in Figure 3. The analysis of binding mode of B2 showed that it has HIs with three residues: CYS-41/LIG: N (cyano-group of pyridine ring) with $\mathrm{HI}$ distance of $2.9 \AA$, ASP-40 LIG:0 (carboxylic group of pyridine ring) with HI distance $3.2 \AA$ A HIS-57 LIG:O (nitro-group of imidazole ring) with HI of $2.1 \AA$ and HIS-57 LIG:O(carboxylic group of pyridine ring) with HI distance $2.3 \AA$ (Figure 3b). Also, ASP-40 LIG:O (nitro-group of imidazole ring) withHI distance $3.0 \AA$, CYS-59 LIG:N (cyano-group of pyridine ring) withHI distance $3.5 \AA$ and CYS-59 LIG:N(cyano-group of pyridine ring) with $\mathrm{HI}$ distance $2.4 \AA$ for $\mathrm{B}_{3}$ (Figure 3c); Likewise, ASP-40 LIG:O(nitro-group of imidazole ring) with HI distance $2.9 \AA$, CYS-41 LIG:O (nitro-group of imidazole ring) withHI distance $3.3 \AA$, PHE-75 LIG:O (nitro-group of imidazole ring) with HI distance $2.3 \AA$, LYS-73 LIG:O(nitro-group of imidazole ring) with $\mathrm{HI}$

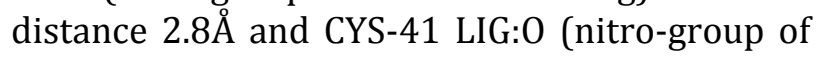
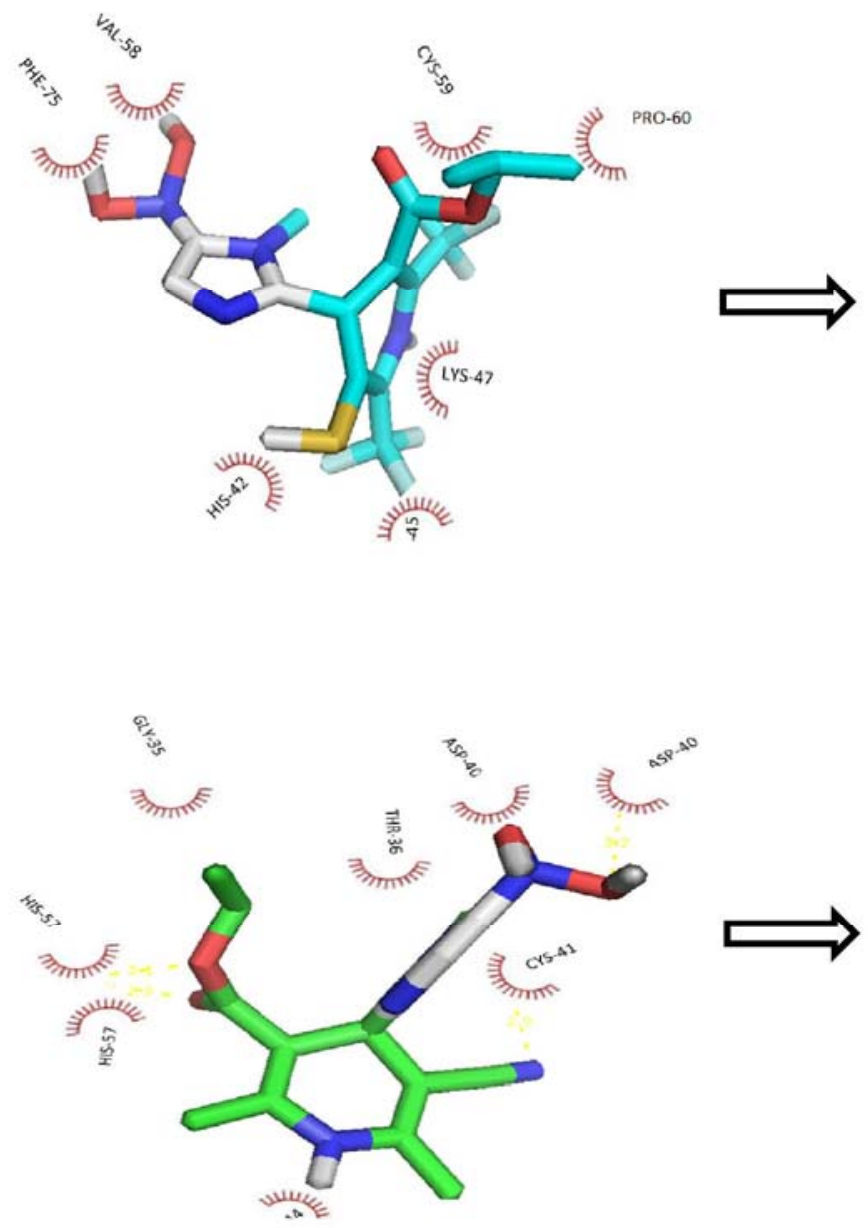

imidazole ring) with $\mathrm{HI}$ distance $2.9 \AA$ for $\mathrm{B}_{4}$ (Figure 3d). Furthermore, ASP-40 LIG:O (nitrogroup of imidazole ring) with HI distance $3.0 \AA$, HIS-57 LIG:O (carboxylic-group of pyridine ring) with HI distance $2.4 \AA$, HIS-57 LIG:O (carboxylicgroup of pyridine ring) with HI distance $1.9 \AA$ and CYS-41 (amino group) LIG:H (Hydrogen) for $\mathrm{B}_{5}$ (Figure 3e).

In addition, CYS-41 LIG:N (cyano-group of pyridine ring) with HI distance $2.9 \AA$, ASP-40 LIG:O (nitro-group of imidazole ring) with $\mathrm{HI}$ distance $2.9 \AA$, HIS-57 LIG:O (carboxylic-group of pyridine ring) with HI distance $2.4 \AA$, and HIS-57 LIG:O (carboxylic-group of pyridine ring) with HI distance $2.1 \AA$ for $B_{6}$ (Figure 3f). Finally, CYS-41 LIG:N (cyano-group of pyridine ring) with $\mathrm{HI}$ distance $3.1 \AA$, HIS-57 LIG:O (carboxylic-group of pyridine ring) with HI distance $2.3 \AA$, THR-58 LIG:O (carboxylic-group of pyridine ring) with $\mathrm{HI}$ distance $2.1 \AA$ and ASP-40 LIG:0 (nitro-group of imidazole ring) with $\mathrm{HI}$ distance $3.2 \AA$ for $\mathrm{B}_{7}$ (Figure 3g).
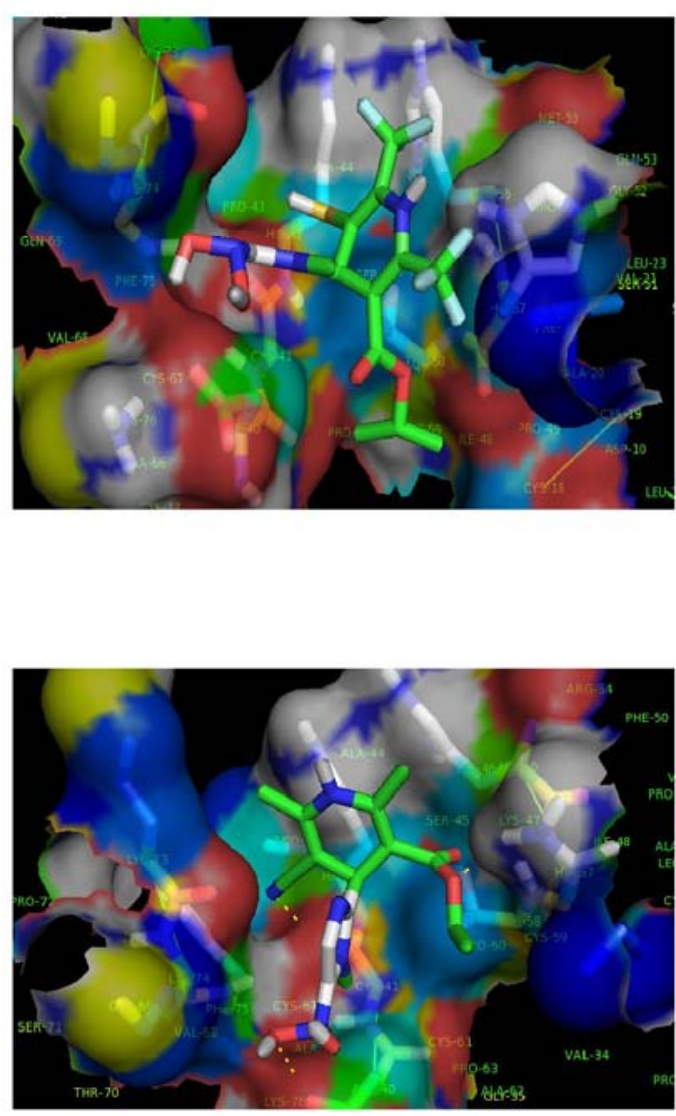


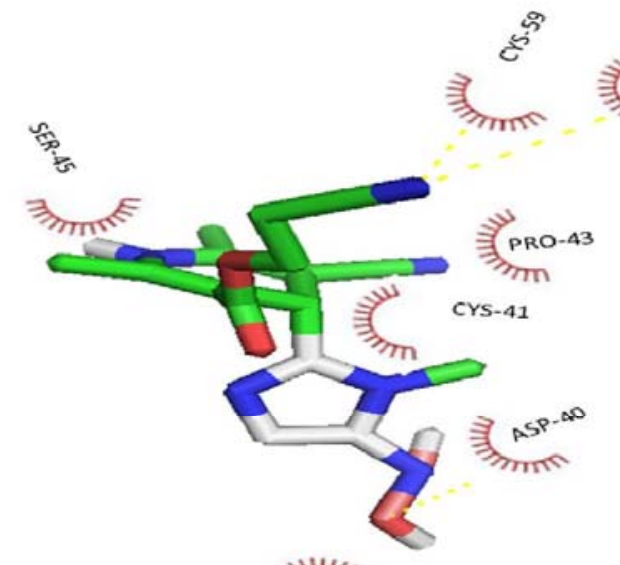

类
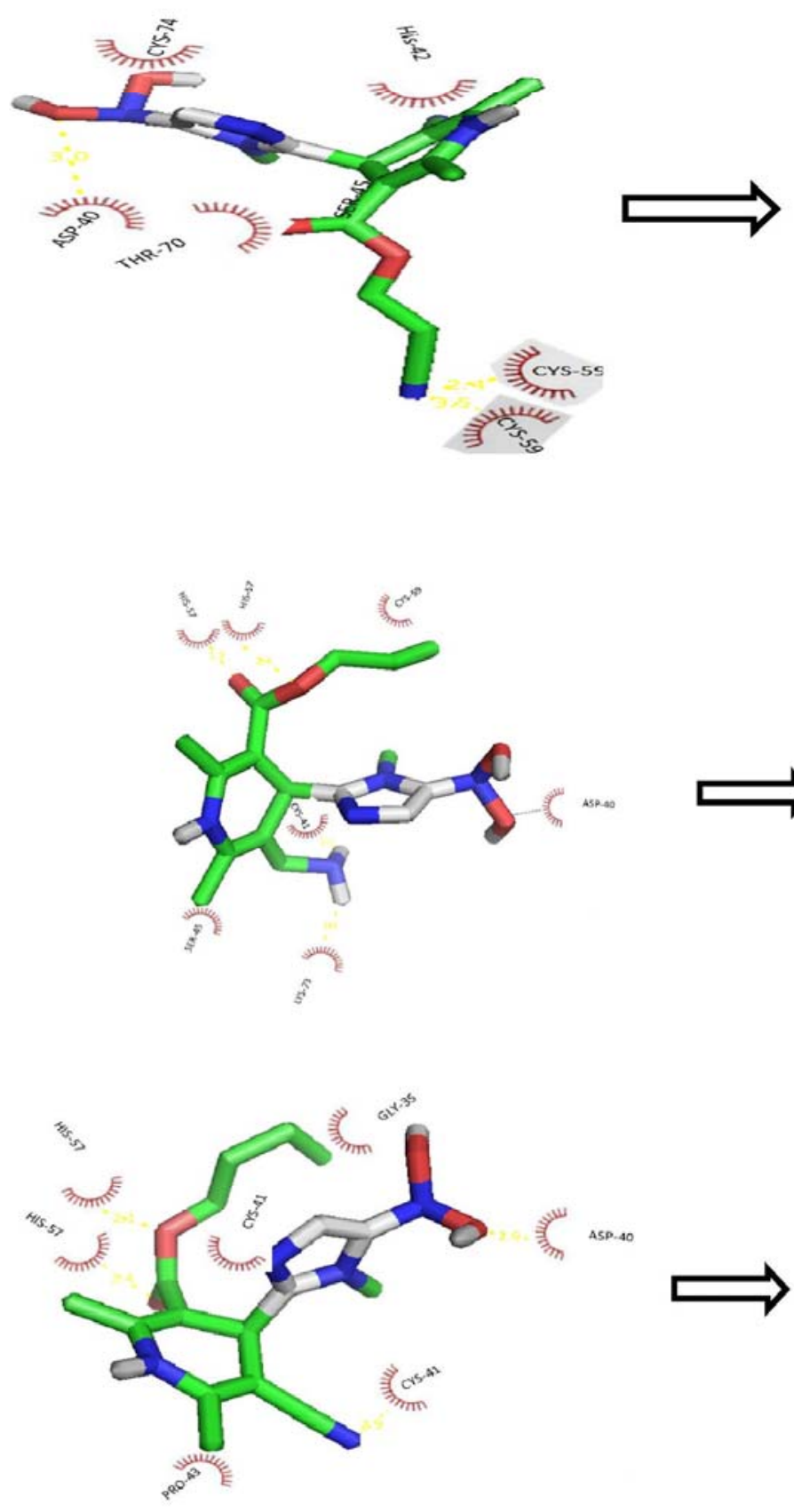
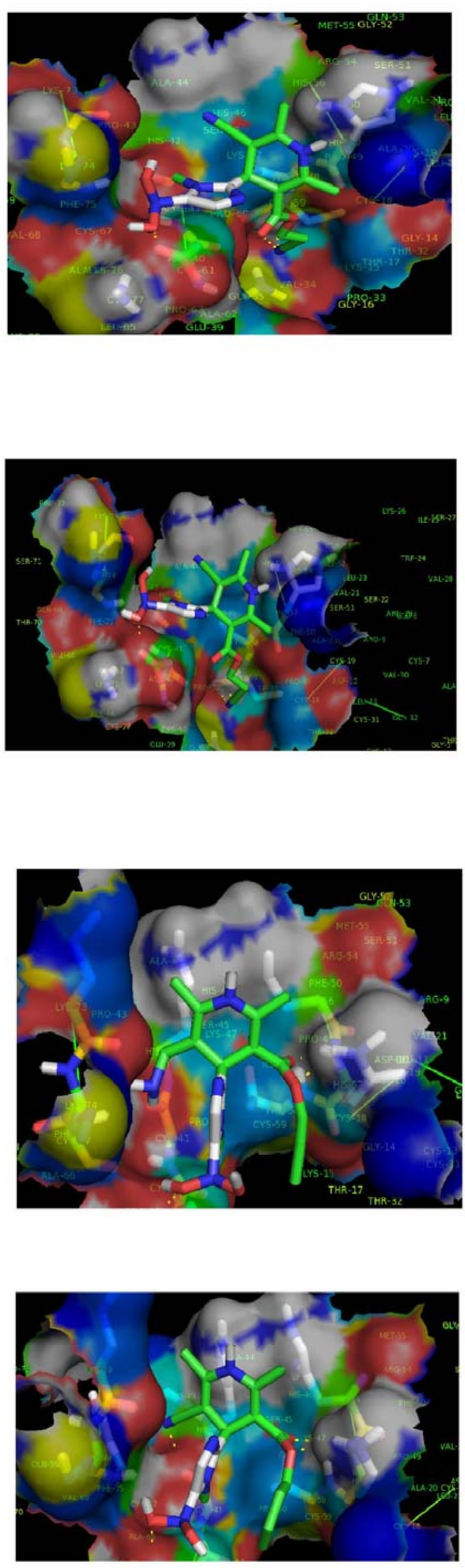

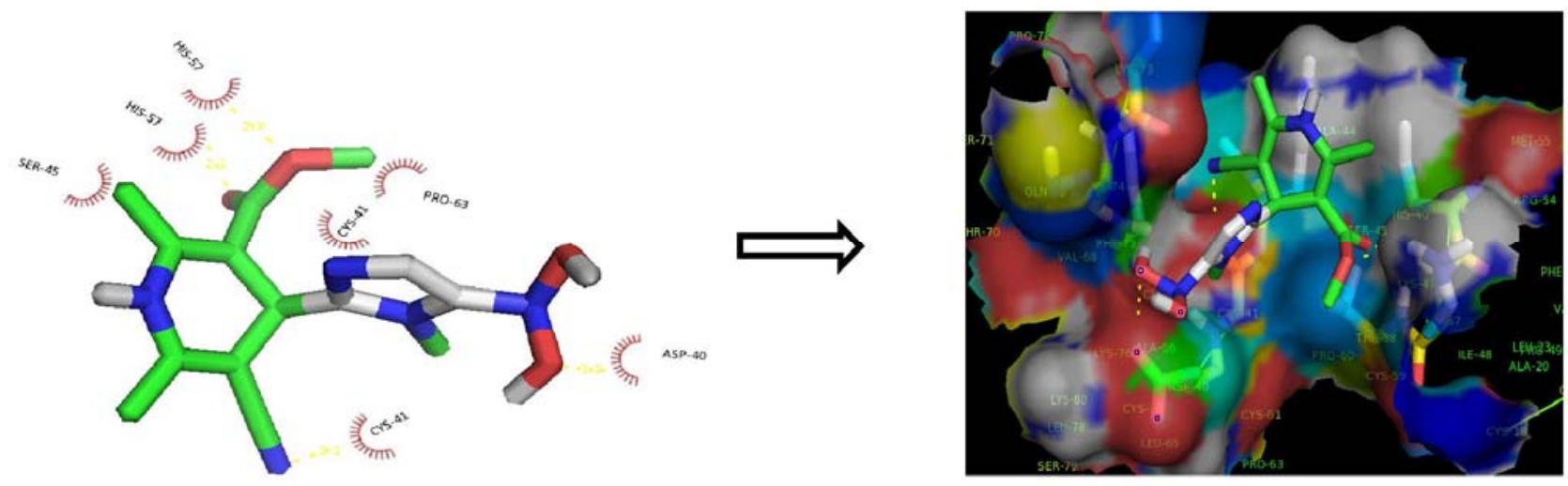

Fig. 3a-g. Binding interaction of $B_{1}-B_{7}$ with 1 IMT

\section{Conclusion}

The study presented quantum chemical calculations of molecular descriptors for the development of a QSAR model that relates the molecular parameters of the studied compounds to their cytotoxicity. In present work, seven compounds which were previously studied for their bioactivity as calcium antagonists, were optimized using DFT method for the calculations of molecular descriptors. The QSAR model developed for calcium channel blocker activity was based on four molecular descriptors the

\section{REFERENCES}

ALJumali MHA. Synthesis, characterization, docking studies and bio-efficacy evaluation of novel 1, 4-dihydropyridine derivatives. Int. J. Sci. Res. 2015;4(12):74-6.

Balasubramanian R, Vijaya Gopal R. Design and in silico analysis of ring-A monosubstituted chalcones as potential anti-inflammatory agents. Bull. Pharm. Res. 2012;2(2): 70-7.

Becke AD. Density-functional thermochemistry. III. The role of exact exchange. J. Chem. Phys. 1993;98(7):5648-52. [DOI: 10.1063/1.464913]

Biovia. Wateridge vista drive, San Diego, CA 92121, USA. 2005.

Dewar MJS, Zoebisch EG, Healy EF, Stewart JJP. Development and use of quantum mechanical molecular models. 76. AM1: A new general purpose quantum mechanical molecular model. J. Am. Chem. Soc. 1985; 107(13):3902-9. [DOI: 10.1021/ja00299a024]

Eroğlu E, Türkmen H, Güler S, Palaz S and Oltulu O. A DFTbased QSARs study of acetazolamide/sulfanilamide derivatives with carbonic anhydrase (CA-II) isozyme inhibitory activity. Int. J. Mol. Sci. 2007;8(2):145-55. [DOI: 10.3390/i8020145]

Goldman BB, Wipke WT. QSD quadratic shape descriptors. 2. Molecular docking using quadratic shape descriptors (QSDock). Proteins 2000;38(1):79-94.

Goodarzi M, Dejaegher B, Vander Heyden Y. Features selection methods in QSAR studies. J. AOAC Int. 2012; 95(3):636-51.

Havas S, Fujimoto W, Close N, McCarter R, Keller J, Sherwin R. The NHLBI workshop on hypertension in Hispanic Americans, Native Americans, and Asian/Pacific Islander Americans. Public Health Rep. 1996;111(5):451-8.
HOMO, dipole moment, solvation energy and average electronic charges on all heteroatoms) in order to avoid multi-collinearity. The selected molecular descriptors were used to model the effectiveness of the compounds as potential CCB and the $\mathrm{IC}_{50}$ calculated from the developed QSAR model agreed with the experimental data. Pharmacophore studies revealed that hydrogen bonds with the amino acid residues in the binding site as well as conformation of the ligand are essential significant features for ligandreceptor binding.

Karelson, M. Molecular Descriptors in QSAR/QSPR. John Wiley \& Sons, New York: 2000.

Lee C, Yang W, Parr RG. Development of the Colle-Salvetti correlation-energy formula into a functional of the electron density. Phys. Rev. B Condens. Matter 1988; 37(2):785-9. [DOI: 10.1103/PhysRevB.37.785]

Lip GYH, Beevers DG. Calcium channel blockers in hypertension: the debate reawakens. J. Hum. Hypertens. 2001;15(2):85-7. [DOI: 10.1038/sj.jhh.1001183]

Liu J, Prakash O, Cai M, Gong Y-X, Huang Y, Wen L, Wen JJ, Huang J-K, Krishnamoorth R. Solution structure and backbone dynamics of recombinant cucurbita maxima trypsin inhibitor-V determined by NMR spectroscopy. Biochemistry 1996;35(5):1516-24.

Meng EC, Shoichet BK, Kuntz ID. Automated docking with grid-based energy evaluation. J. Comp. Chem. 1992;13(4): 505-24. [DOI: 10.1002/jcc.540130412]

Miri R, Javidnia K, Mirkhani H, Kazemi F, Hemmateenejad B, Edraki N, Mehdipour AR. Synthesis and in vitro dual calcium channel antagonist-agonist activity of some 1, 4Dihydo-2, 6-dimethyl-3-nitro and cyano-4-(1-methyl-5nitro-1H-imidazol-2-yl)-5-pyridinecarboxylates. Daru J. Pharm. Sci. 2008;16(4):263-70.

Morris GM, Lim-Wilby M. Molecular docking. Methods Mol. Biol. 2008;443:365-82. [DOI: 10.1007/978-1-59745-1772_19]

Nantasenamat C, Isarankura-Na-Ayudhya C, Naenna T, Prachyasittikul V. A practical overview of quantitative structure-activity relationship. Excli J. 2009;8:74-88.

Ogah OS, Rayner BL. Recent advances in hypertension in sub-Saharan Africa. Heart 2013;99(19):1390-7. [DOI: 10.1 136/heartjnl-2012-303227] 
Olson KR. Poisoning and Drug Overdose. $6^{\text {th }}$ edition, McGraw-Hill Education, Columbus, OH: 2011.

Oyebamiji A and Semire B. Studies of 1, 4-Dihydropyridine derivatives for anti-breast cancer (MCF-7) activities: combinations of DFT-QSAR and docking methods. New York Sci. J. 2016;9(6):58-66. [DOI: 10.7537/marsnys 0906 1610]

Ponce YM, Garit JAC, Torrens F, Zaldivar VR, Castro EA. Atom, atom-type, and total linear indices of the "molecular pseudograph's atom adjacency matrix": application to QSPR/QSAR studies of organic compounds. Molecules 2004;9(12):1100-23. [DOI: 10.3390/912011 00]

Sharma V, Kumar V. Efficient way of drug designing: a comprehensive review on computational techniques. Bull. Pharm. Res. 2014;4(3):118-23.

Sharma V, Wakode SR, Lather V, Mathur R, Fernandes MX. Structure based rational drug design of selective phosphodiesterase-4 ligands as anti-inflammatory molecules. Bull. Pharm. Res. 2011;1(2):33-40.

Singh PP, Srivastava HK, Pasha FA. DFT-based QSAR study of testosterone and its derivatives. Bioorg. Med. Chem. 2004;12(1):171-7. [DOI: 10.1016/j.bmc.2003.11.002]

Stewart JJP. Optimization of parameters for semiempirical methods II. Applications. J. Comp. Chem. 1989;10(2):22164. [DOI: 10.1002/jcc.540100209]

Rani S, Ajeet, Kumar A. Designing of sulfanilamide/ sulfacetamide derivatives as human topoisomerase II inhibitor: A docking approach. Am. J. Pharmcol. Sci. 2014;2(2):42-6. [DOI: 10.12691/ajps-2-2-3]

Todeschini R, Consonni V. Handbook of Molecular Descriptors, Wiley-VCH Verlag, Weinheim, Germany: 2000.

Tropsha A. Best practices for QSAR model development, validation and exploitation. Mol. Inform. 2010;29(6-7): 476-88.

Wold S, Eriksson L. Statistical validation of QSAR results. In Waterbeemd, Han van de. Chemometric methods in molecular design, Weinheim, Germany: 1995; 309-18.

Whitworth JA. 2003 World Health Organization (WHO)/International Society of Hypertension (ISH) statement on management of hypertension. J. Hypertens. 2003;21(11):1983-92. [DOI: 10.1097/01.hjh.000008475 1.37215.d2]

Zhang L, Wan J, Yang G. A DFT-based QSARs study of protoporphyrinogen oxidase inhibitors: phenyl triazolinones. Bioorg. Med. Chem. 2004;12(23):6183-91. [DOI: 10.1016/j.bmc.2004.08.046] 